\title{
Parameters Substantiation of Guide Surface of Flat Material into the Processing Area
}

\author{
Gayrat Bahadirov, Makhmarajab Musirov, Kudratkhon Bakhadirov
}

\begin{abstract}
The transporting and feeding devices of technological machines have to ensure the transportation and supply of any sheet material, including leather semi-finished product without folds, into the working area of the rolling pair.

In the transition section between the feed conveyor and the roll pair, when there is an insufficient friction between the sheet material and the surface of the lower work roll, problems may arise, i.e. accumulation, twisting or retention of sheet material will occur. To prevent such cases, it is recommended to use the guide surface of the processed leather semi-finished product in the processing zone, which provides a smooth transition of the leather semi-finished product to the contact area of the roll pair. The paper presents theoretical preconditions for determining the type (shape) of the guide surface of a flat material into the processing zone. The problem of smooth supply of flat material to the processing zone of the roll pair has been solved. To solve the problem of smooth feeding of the flat material into the processing zone of the roll pair, by selecting the curve of the guide surface, differential equations of material motion are finalised. By the numerical method Graphic dependences is derived that allow depending on the initial parameters of the machine and the leather semi-finished product determining the required parameters of the guide surface of conveying device, providing a smooth supply of flat material into the processing zone of the working roll pair.
\end{abstract}

Keywords: string conveyor, feed, flat material, guiding device, deformation.

\section{INTRODUCTION}

The quality of the processed flat material, for example, finished leather is affected by technological processes, therefore, after the implementation of each of them, it is necessary to analyze the state of the processed material. Experimental studies in the leather industry are aimed at solving complex multifactor problems, the result of which determines the rational modes of technological procedures for processing leather raw materials. Physical-mechanical properties of the leather semi-finished product vary depending on its moisture content $[1,2]$.

\section{LITERATURE REVIEW}

It is known [1] that the supply of the processed material to the processing zone of the roll pair without creases and

Revised Manuscript Received on April 25, 2020.

* Correspondence Author

Gayrat Bahadirov*, Prof., Doctor of Technical Sciences, Institute of Mechanics and Seismic Stability of Structures of the Academy of Sciences of the Republic of Uzbekistan.

Makhmarajab Musirov, Junior Researcher, Institute of Mechanics and Seismic Stability of Structures of the Academy of Sciences of the Republic of Uzbekistan.

Kudratkhon Bakhadirov, assistant professor, Ph.D Tashkent state technical university named after Islam Karimov Tashkent, Uzbekistan.

(c) The Authors. Published by Blue Eyes Intelligence Engineering and Sciences Publication (BEIESP). This is an open access article under the CC BY-NC-ND license (http://creativecommons.org/licenses/by-nc-nd/4.0/) jamming is an important task in various industries, because this leads to the elimination of defects and losses of the finished product. Therefore, the implementation of such measures in leather production ultimately leads to a significant saving of raw materialsIn [4], the authors investigated the conditions for ensuring free sliding of homogeneous bodies in a bent cylinder. The curvature value of a bent cylinder to ensure free sliding of the body along it was determined.

The effect of curvature of a curved surface on the sliding of rock mass with friction was studied in [5]. There the authors used two-dimensional boundary element methods and rock fracture mechanics to determine the effect of curvature of a curved surface on its sliding.

In [6], the conditions for the supply and capture of a leather semi-finished product between a roll pair were investigated. The influence of the shaft torque on the conditions of capture of the processed material was determined.

The authors of [7] investigated the condition for a viscous fluid flow along a curved surface with sliding. The equation of the energy of an electrically conductive fluid effect was simulated.

In [8], the nanofluid flow along a curved sheet was studied. The curvature parameters of the conveying curved sheet were studied taking into account the viscosity of a nanofluid.

The problems of sliding flow conditions in a curvilinear channel consisting of two cylindrical surfaces were studied [9]. The authors considered two particular cases of flow slip during rotation of a cylindrical surface, as well as at its stationary state. The dependences of the critical values of the criteria for the instability of the sliding flow on the ratio of the radii of the concave and convex walls and on the slip coefficient with respect to velocity were determined.

In [10], the authors proposed an innovative model of a vacuum device to increase reliability and ensure piece capture from a stack of skin layers by means of suction. The device also provides the motion of the stack of skin layers to the area of their further cutting.

The studies in [11] give an assessment of a new sustainable continuous system for treating bovine skin. Using the prototype [12], the process of dehydration of bovine skins was carried out. As a result of this new process, dehydrated skin with optimal physical and chemical characteristics was obtained; these characteristics allowed its subsequent tanning by immersion in aqueous solutions of chemical products.

Previously, we have developed a device for smooth feeding the flat material into the processing zone.

Published By:

Blue Eyes Intelligence Engineering DOI: $10.35940 /$ ijeat.D7655.049420

Journal Website: www.ijeat.org

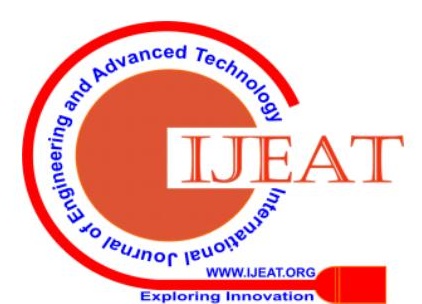


The device consists of a frame on which a guide surface is mounted, enveloped by the infinite feed strings of the conveyor [2, 13]. In [14], we have determined the strain characteristics of a leather semi-finished product. The influence of the pressure of the squeeze shafts on the strain of leather semi-finished product was determined. The work [15] presents the results of determining the amount of moisture removed on the velocity and the multiplicity of feeding a leather semi-finished product between squeezing shafts when the pressure of squeezing shafts changes.

\section{RESEARCH METHODOLOGY}

For an oriented and smooth feeding of flat material 1 into the treatment zone by a roll pair, we have developed a device consisting of a string conveyor 2 for moving flat material 1 , the envelope rolls of the conveyor 3 and 4 , equipped with instruments 5 for guiding the flat material 1 made of a metal sheet with recesses for the strings 6 and installed on the frame 7 (Fig. 1) [13].

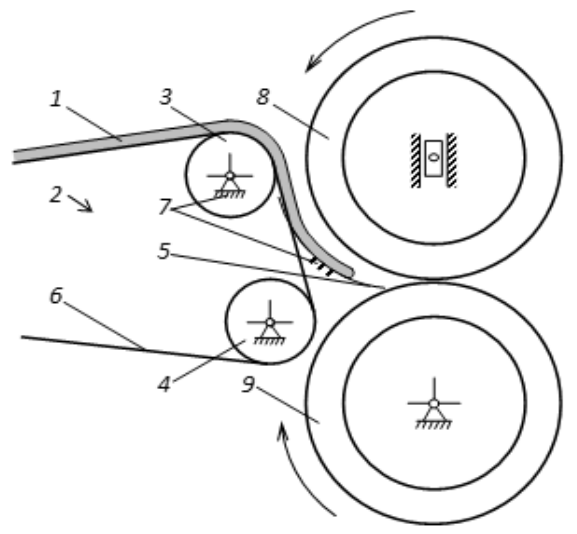

Fig. 1 - Diagram of a roller machine with a device guiding flat material into the processing zone

Instruments 5 for guiding the flat material 1 is made curved, with a concave surface. In operation, the flat material 1 being on the strings 6 , of the conveyor 2 moves and transfers to the tool 5 to be directed into the contact zone of the working shafts 8 and 9 .

Consider the guide surface. In a first approximation, we take a flat material in the form of a material point moving along a guide surface. The system of forces acting on a material point is determined using the Newton's II law [16] (Fig. 2).

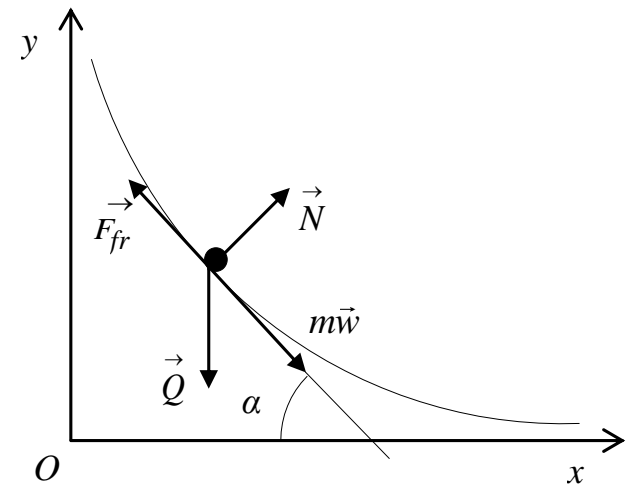

Fig. 2 - Calculation scheme for determining the forces acting on a material point moving along a guide surface $m \vec{w}=\vec{Q}+\vec{F}_{f r}+\vec{N}$. where $\vec{Q}$ - is the force of gravity, $\vec{F}_{f r}$ is the force of friction, $\vec{N}$ is the force of the normal reaction.

We project equation (1) in the tangent and normal directions and we obtain the following equations:

$$
\begin{aligned}
& \vec{\tau}: m \frac{d v}{d t}=Q \sin \alpha-F_{f r} . \\
& \vec{n}: m \frac{v^{2}}{R}=-Q \cos \alpha+N .
\end{aligned}
$$

The force of normal reaction is determined from equation (3):

$$
N=m \frac{v^{2}}{R}+Q \cos \alpha
$$

We know that the friction force is determined by the Coulomb law [16].

$$
F_{f r}=f N \text {. }
$$

Substituting expressions (4) and (5) in (2), we obtain the following equation for the motion of a material point along a tangent line:

$$
m \frac{d v}{d t}=-Q \cos \alpha(f-\operatorname{tg} \alpha)-m \frac{v^{2}}{R} f .
$$

To determine the radius of curvature of the curve of the guide surface on the $O x y$ plane (Fig. 2), we write the following [17]:

$$
R^{-1}= \pm \frac{y^{\prime \prime}}{\left(1+y^{\prime 2}\right)^{\frac{3}{2}}},
$$

where the angular coefficient of the curve $y^{\prime}$ has the following form:

$$
y^{\prime}=\operatorname{tg} \alpha \text {. }
$$

Since we are considering a concave surface, we choose the negative value of this expression.

Using expressions (7) and (9), we write formula (6) in the following form:

$$
m \frac{d v}{d t}=-\frac{Q}{\sqrt{1+y^{\prime 2}}}\left(f-y^{\prime}\right)+m f v^{2} \frac{y^{\prime \prime}}{\left(1+y^{\prime 2}\right)^{\frac{3}{2}}} .
$$

According to our conditions, a flat material moves along a concave surface at a constant velocity. Therefore, for the left side of equation (9) equality $m \frac{d v}{d t}=0$ is appropriate. As a result of simplification, we obtain the following equation:

$$
y^{\prime \prime}=\frac{Q}{m f v^{2}}\left(f-y^{\prime}\right)\left(1+y^{\prime 2}\right) \text {. }
$$

For the normal course of the process, the resulting solution (10) must obey the following conditions:

1. The function must be decreasing, i.e. $y^{\prime}<0$, which provides a reduction in the curve along the $O x$ axis.

2 . To ensure the concavity of the curve we take $y^{\prime \prime} \geq 0$.

To solve differential equation (10), in the first approximation, the satisfying boundary conditions are:

$$
\left\{\begin{array}{l}
y(0)=h \\
y(l)=0
\end{array}\right.
$$

and a straight line function is $y=f(x)$ :

Published By:

Blue Eyes Intelligence Engineering

\& Sciences Publication

(c) Copyright: All rights reserved. 


$$
y=h\left(1-\frac{x}{l}\right)
$$

$$
y^{\prime}=\frac{h}{l} \text {. }
$$

Using expressions (12) and (13), we write the differential equation (10) in the following form:

$$
y^{\prime \prime}=\frac{Q}{m f v^{2}}\left(f+\frac{h}{l}\right)\left(1+\frac{h^{2}}{l^{2}}\right) \equiv Q_{0}>0 .
$$

A solution satisfying the boundary conditions is found (11),

$y^{\prime}=Q_{0} x+C_{1}$.

$y=Q_{0} \frac{x^{2}}{2}+C_{1} x+C_{2}$.

$C_{1}=-\frac{h}{l}-\frac{1}{2} Q_{0} l, C_{2}=h$.

As a result, we obtain the following parabola equation

$y=\frac{1}{2} Q_{0} x^{2}-\frac{h}{l}\left(1+\frac{Q_{0} l^{2}}{2 h}\right) x+h$,

where the decrease in the curve of the line along the $O x$ axis is

$y^{\prime}(0)=C_{1}=-\frac{h}{l}-\frac{1}{2} Q_{0} l$

$y^{\prime}(l)=Q_{0} l+C_{1}=-\frac{h}{l}+\frac{1}{2} Q_{0} l<0$.

Bearing in mind that the curve should approach the $O x$ axis, we obtain the following condition,

$$
Q_{0} \leq \frac{2 h}{l^{2}}
$$

Thus, when condition (18) is fulfilled, the guide surface provides a smooth supply of flat material into the treatment zone.

In the second approximation, the first-order derivatives of the solution obtained in the first approximation (17) are substituted on the right side of differential equation (10) and after some transformations we obtain

$$
y^{\prime \prime}=\frac{Q}{m f v^{2}}\left(f-Q_{0} x-C_{1}\right)\left(1+\left(Q_{0} x+C_{1}\right)^{2}\right) \text {. }
$$

Simplifying this equality, we obtain the following:

$$
\begin{aligned}
y^{\prime \prime} & =\frac{Q}{m f v^{2}}\left\{\left(f-C_{1}\right)\left(1+C_{1}^{2}\right)+\left[2 Q_{0} C_{1}\left(f-C_{1}\right)-Q_{0}\left(1+C^{2}\right)\right] x+\right. \\
& \left.+\left[\left(f-3 C_{1}\right) Q_{0}^{2}\right] x^{2}-Q_{0}^{3} x^{3}\right\}
\end{aligned}
$$

We introduce the notation and write the resulting expression (20) in the following simplified form:

$y^{\prime \prime}=Q_{1}+Q_{2} x+Q_{3} x^{2}+Q_{4} x^{3}$,

where,

$$
\left\{\begin{array}{l}
Q_{1}=\frac{Q}{m f v^{2}}\left(f-C_{1}\right)\left(1+C_{1}^{2}\right), \\
Q_{2}=\frac{Q}{m f v^{2}}\left(2 Q_{0} C_{1}\left(f-C_{1}\right)-Q_{0}\left(1+C_{1}^{2}\right)\right), \\
Q_{3}=\frac{Q Q_{0}}{m f v^{2}}\left(f-3 C_{1}\right), \\
Q_{4}=-\frac{Q Q_{0}^{3}}{m f v^{2}} .
\end{array}\right.
$$

Integrating differential equation (21) twice in a row, we obtain the following productive solution:

$y=\frac{1}{2} Q_{1} x^{2}+\frac{1}{6} Q_{2} x^{3}+\frac{1}{12} Q_{3} x^{4}+\frac{1}{20} Q_{4} x^{5}+C_{3} x+C_{4}$.

In the obtained solution, the values of the integrated constants $C_{3}$ and $C_{4}$ are found from the boundary conditions (11).

At $x=0, y=h, C_{4}=h$,

At $x=l, y=0$,

$C_{3}=-\frac{h}{l}-\left(\frac{1}{2} Q_{1} l+\frac{1}{6} Q_{2} l^{2}+\frac{1}{12} Q_{3} l^{3}+\frac{1}{20} Q_{4} l^{4}\right)$,

$y^{\prime}(0)=C_{3}=-\frac{h}{l}-\left(\frac{1}{2} Q_{1} l+\frac{1}{6} Q_{2} l^{2}+\frac{1}{12} Q_{3} l^{3}+\frac{1}{20} Q_{4} l^{4}\right)<0$,

$y^{\prime}(l)=-\frac{h}{l}+\frac{1}{2} Q_{1} l+\frac{1}{3} Q_{2} l^{2}+\frac{1}{4} Q_{3} l^{3}+\frac{1}{5} Q_{4} l^{4}<0$.

Fig. 3 shows the graphs of dependence of $y$ on $x$, constructed according to formulas (17) and (23) at equal values.

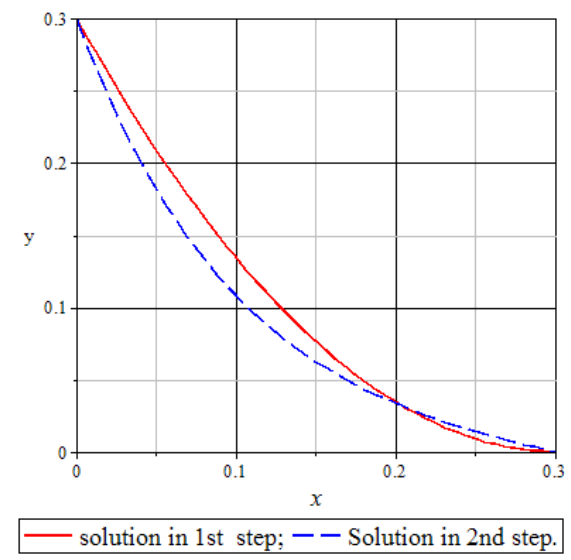

Fig. 3 - Comparative graphs of the dependence of $y$ on $x$ plotted by formulas (17) and (23)

So, a flat material moves, sliding at a constant velocity under the action of internal and external forces, such as the gravity, friction, and internal stresses (Fig. 4).

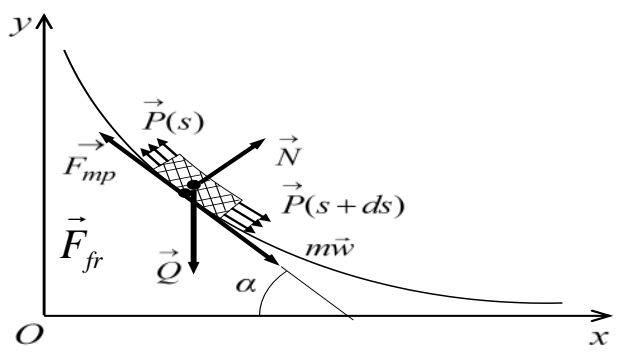

Fig. 4 - System of forces acting on a flat material

Published By:

Blue Eyes Intelligence Engineering

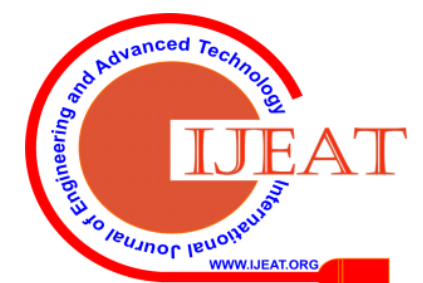


In the problem under consideration, we take into account the internal forces. These forces express the effect of the remains of flat material on the selected piece from this material.

We write down all the forces acting on a piece of flat material in the following form:

$$
\rho \vec{w} d s=(\vec{P}(s+d s)-\vec{P}(s))+\vec{N} d s+\vec{F}_{f r} d s+\vec{Q} d s,
$$

where $\vec{P}(s)$ - is the internal stress of a flat material

corresponding to a distance $s, \vec{P}(s+d s)$ - is the internal stress of a flat material corresponding to a distance, $s+d s$, $\vec{N}$ - is the normal reaction force, $\vec{F}_{f r}$ is the friction force, $\vec{Q}$ is the gravity.

Having simplified expression (24), we write the projections along the tangent and normal axes.

Given that $P=E \frac{d y}{d x}$ and $\frac{d P}{d x}=E \frac{d^{2} y}{d x^{2}}$ [18], we write the projection of forces on the tangent and normal axes, from equation (24),

$\vec{\tau}: \rho d s \frac{d v}{d t}=E \frac{d^{2} y}{d x^{2}}+F_{f r} d s+\rho g d s \sin \alpha$,

$\vec{n}: \rho d s \frac{v^{2}}{R}=N d s-\rho g d s \cos \alpha$.

Since, during the movement of a piece of flat material, its velocity is constant, therefore, the following condition is met

$\frac{d v}{d t}=0$

Using expressions (5), (7), (8), (26) and (27), we write the differential equation of the curve of the guide surface (25) on the $O x y$ plane in the following form:

$$
y^{\prime \prime}=\frac{g\left(f-y^{\prime}\right)\left(1+y^{\prime 2}\right)}{f v^{2}+\frac{E}{\rho}\left(1+y^{\prime 2}\right)^{\frac{3}{2}}} \text {. }
$$

We choose a straight line function $y=f(x)$ satisfying the initial conditions $y(0)=h$ and $y(l)=0$.

$$
y=h\left(1-\frac{x}{l}\right),
$$

Substituting the selected function of the straight line (29) on the right side of differential equation (28) we obtain the following expression:

$$
y^{\prime \prime}=\frac{g\left(f-\frac{h}{l}\right)\left(1+\frac{h^{2}}{l^{2}}\right)}{f v^{2}+\frac{E}{\rho}\left(1+\frac{h^{2}}{l^{2}}\right)^{\frac{3}{2}}} \equiv G_{0} .
$$

It can be seen, expression (30) always has a positive value. Therefore, the described surface will be concave, i.e.,

$G_{0}>0$.

Integrating the obtained differential equation (31) twice, we obtain the parabola equation and determine the integration constants from the boundary conditions:

$$
\begin{aligned}
& y=\frac{1}{2} G_{0} x^{2}+C_{1} x+C_{2}, \\
& y(0)=h, C_{2}=h,
\end{aligned}
$$

$y(l)=0, C_{1}=-\frac{h}{l}-\frac{1}{2} G_{0} l$.

Considering that, with an increase in the value of $x$, the curve approaches the $O x$ axis, then we write the following:

$$
\begin{aligned}
& y^{\prime}(0)=C_{1}=-\frac{h}{l}-\frac{1}{2} G_{0} l<0, \\
& y^{\prime}(l)=-\frac{h}{l}+\frac{1}{2} G_{0} l<0 .
\end{aligned}
$$

As a result, we obtain a condition that must be satisfied for given values of $h$ and $l$.

$$
G_{0}<\frac{2 h}{l^{2}} \text {. }
$$

Let's plot the chart at the values we set: $v=\frac{1}{3} \mathrm{~m} / \mathrm{s}$, $E=10^{5} \mathrm{~N} / \mathrm{m}, \rho=1 \mathrm{~kg} / \mathrm{m}^{3}$, at $f=0.5, h=0.3 \mathrm{~m}, l=0.3$ m (Fig. 5).

Further, differentiating expression (32) once depending on $x$, we substitute in the right side of equality (28). Using the numerical Runge-Kutta method [19], we calculate the differential equation (28) using the "Maple" program [20] (Fig. 5).

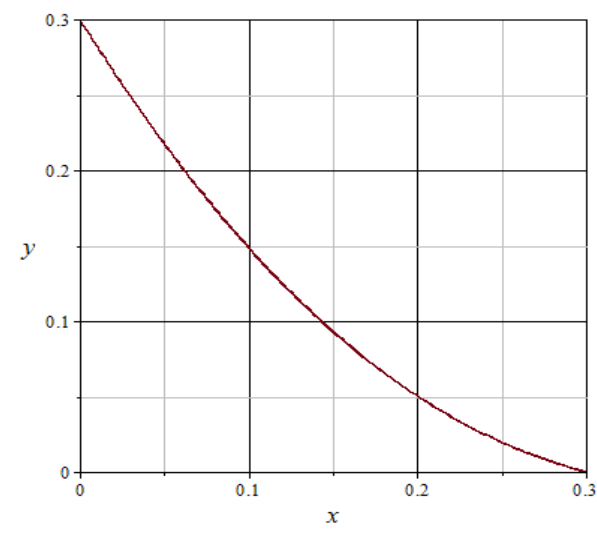

Fig. 5 - Graphic solution obtained for a flat material

Substitute equation (32) into (28) and, after simplifications, we obtain the following differential equation:

$$
y^{\prime \prime}=\frac{g\left(G_{1}+G_{2} x+G_{3} x^{2}+G_{4} x^{3}\right)}{f v^{2}+\frac{E}{\rho}\left(1+C_{1}^{2}+2 G_{0} C_{1} x+G_{0}^{2} x^{2}\right)^{\frac{3}{2}}} .
$$

then,

$$
\left\{\begin{array}{l}
G_{1}=g\left(f-C_{1}\right)\left(1+C_{1}^{2}\right), \\
G_{2}=g\left(2 G_{0} C_{1}\left(f-C_{1}\right)-G_{0}\left(1+C_{1}^{2}\right)\right), \\
G_{3}=g G_{0}^{2}\left(f-3 C_{1}\right), \\
G_{4}=-g G_{0}^{3} .
\end{array}\right.
$$

Similar solutions were obtained when solving the differential equations of the guide surface (28) and (36) in the Maple graphics program.

So, performing calculations step by step in such a sequence, we can get all the partial solutions.

Preliminary experiments showed that the presence of a device for guiding flat material prevents its aggregation, twisting and delay between the feed conveyor and the lower working shaft and ensures its feed into the processing zone (Fig. 6) [2, 6, 14].

Published By:

Blue Eyes Intelligence Engineering

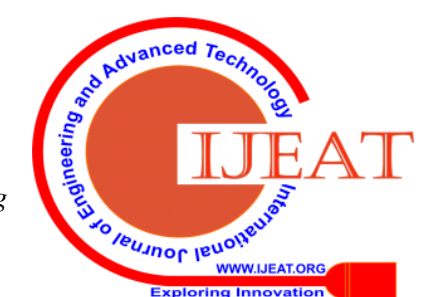




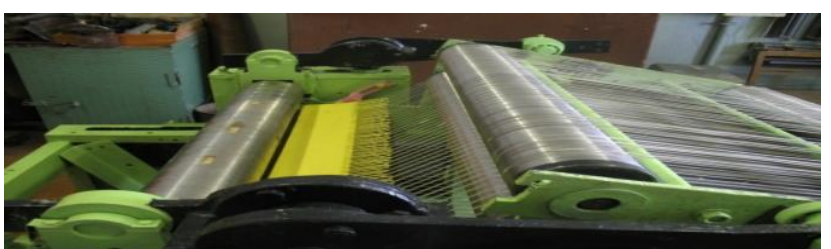

Fig. 6 - The experimental stand of the roller machine with a device for directing flat material into the processing zone

To substantiate the parameters of the guide surface, the problem must be solved taking into account the friction coefficient of the rubbing pairs and the motion velocity of this material.

\section{DISCUSSION}

Equations (10) and (28) that we derived will be used in determining and choosing rational parameters of the guide surface of technological machines taking into account the properties of the processed material.

Depending on the requirements for processing flat material and the variety of technological processes performed, it is possible to obtain various types and shapes of the guide surface using these equations.

\section{RESULT}

The problem of smooth supply of flat material to the processing zone of the roll pair has been solved. Differential equations (10) and (28) are derived for choosing the curve of the guide surface of a flat material into the processing zone of a roll pair. Based on the solution of differential equation (28), the bending shape of the guide surface is obtained in the form of a parabolic line (Fig. 5).

\section{CONCLUSION}

The graphical solution obtained by numerical method (Fig. 6) coincides with the graph of the solution obtained with step by step method (Fig. 4). The resulting graphic solutions due to the effect of Young modulus have the form of a straight line. This graphical solution gives us the opportunity to determine the necessary parameters of the guide surface of the conveying device, providing a smooth supply of flat material in the area of the working roll pair.

\section{REFERENCES}

1. Burmistrov, A.G. Machines and apparatus for the production of leather and fur / A.G. Burmistrov -M.: KolosS, 2006. -384 p.

2. Bahadirov, G.A. The mechanics of the squeezing roll pair. - T.: Fan, 2010. $-156 \mathrm{p}$.

3. Leather Processing \& Tanning Technology Handbook. NIIR Board of Consultants \& Engineers, 2011. ISBN-10: 8190568590, p. 592.

4. Gallardo, J. P., Pettersen, B., \& Andersson, H. I. (2013). Effects of free-slip boundary conditions on the flow around a curved circular cylinder. Computers \& Fluids, 86, 389-394. doi:10.1016/j.compfluid.2013.07.023.

5. Richard, A. Schultz. Mechanics of curved slip surfaces in rock. Engineering Analysis with Boundary Elements 10 (1992) 147-154.

6. Bahadirov, G.A., Nabiev, A.M., Umarov, A.A. Investigation of the process of squeezing a wet leather semi-finished product between a roller pair. International Journal of Advanced Research in Science, Engineering and Technology. India. Volume 6, Issue 7, July 2019. Pp. 10240-10246. http://www.ijarset.com/volume-6-issue-7.html.

7. Muhammad, R., \& Khan, M. I. (2019). Magnetohydrodynamics
(MHD) radiated nanomaterial viscous material flow by a curved surface with second order slip and entropy generation. Computer Methods and Programs in Biomedicine, 105294. doi:10.1016/j.cmpb.2019.105294.

8. Hayat, T., Qayyum, S., Alsaedi, A., \& Ahmad, B. (2020). Entropy generation minimization: Darcy-Forchheimer nanofluid flow due to curved stretching sheet with partial slip. International Communications in Heat and Mass Transfer, 111, 104445. doi:10.1016/j.icheatmasstransfer.2019.104445.

9. Avramenko, A.A., Kuznetsov, A.V. Instability of a slip flow in a curved channel formed by two concentric cylindrical surfaces. European Journal of Mechanics B/Fluids. Volume 28, Issue 6 , November-December 2009, Pages 722-727. https://doi.org/10.1016/j.euromechflu.2009.06.003.

10. Failli, F., \& Dini, G. (2004). An Innovative Approach to the Automated Stacking and Grasping of Leather Plies. CIRP Annals, 53(1), 31-34. doi:10.1016/s0007-8506(07)60638-6.

11. Bacardit, A., Baquero, G., Sorolla, S., \& Ollé, L. (2015). Evaluation of a new sustainable continuous system for processing bovine leather. Journal of Cleaner Production, 101, 197204. doi:10.1016/j.jclepro.2015.04.012.

12. AIICA, 2010. WO 2010/070571 A2. Procedure of the Tanning of Skins, Material Obtained during Said Procedure and Device.

13. Bahadirov, G.A., Khusanov, K.B., Abdukarimov, A., Bahadirov, K.G., Kasimov, H.Kh. Device for controlling the supply of material to the processing zone // Patent of the Republic of Uzbekistan No. FAP 00773. 2012. No. 11 (139). -P. 63. http://baza.ima.uz/\#newsletters.

14. Bahadirov, G., Tsoy, G., Nabiev, A., Umarov, A. Experiments on Moisture Squeezing from a Leather Semi-Finished Product. International Journal of Recent Technology and Engineering (IJRTE), Volume-8 Issue-5, January 2020, ISSN: 2277-3878 (Online) Published By: Blue Eyes Intelligence Engineering \& Sciences Publication. Pp. 3367-3371. doi:10.35940/ijrte.E6125.018520.

15. Amanov, A., Bahadirov, G., Amanov, T., Tsoy, G., \& Nabiev, A. (2019). Determination of Strain Properties of the Leather SemiFinished Product and Moisture-Removing Materials of Compression Rolls. Materials, 12(21), 3620. doi:10.3390/ma12213620.

16. Buchholz, N.N. The main course of theoretical mechanics. Part 1. Kinematics, statics, dynamics of a material point. Textbook / N.N. Buchholz. - St. Petersburg: Doe, 2009.- 480 p.

17. Castro, I., \& Castro-Infantes, I. (2016). Plane curves with curvature depending on distance to a line. Differential Geometry and Its Applications, 44, 77-97. doi:10.1016/j.difgeo.2015.11.002.

18. Małkowski, P., \& Ostrowski, Ł. (2017). The Methodology for the Young Modulus Derivation for Rocks and Its Value. Procedia Engineering, 191, 134-141. doi:10.1016/j.proeng.2017.05.164.

19. Jackson, K. R., \& Butcher, J. C. (1988). The Numerical Analysis of Ordinary Differential Equations; Runge-Kutta and General Linear Methods. Mathematics of Computation, 51(183), 377 doi:10.2307/2008600.

20. Sharma, A.K. Text Book Of Circles And Parabola. Discovery Publishing House, New Drlhi-110002, 2005, ISBN 817141995X, 9788171419951. P.308.

\section{AUTHORS PROFILE}

Bahadirov Gayrat Atahanovich, Prof., Doctor of Technical Sciences, Institute of Mechanics and Seismic Stability of Structures of the Academy of Sciences of the Republic of Uzbekistan. E-mail: instmech@rambler.ru

Musirov Makhmarajab, Junior Researcher, Institute of Mechanics and Seismic Stability of Structures of the Academy of Sciences of the Republic of Uzbekistan.

E-mail: musirov.mech.1992@mail.ru

Bakhadirov Kudratkhon Gayratovich, assistant professor, Ph.D Tashkent state technical university named after Islam Karimov Tashkent, Uzbekistan. E-mail: bahadirov@gmail.com

Published By:

Blue Eyes Intelligence Engineering

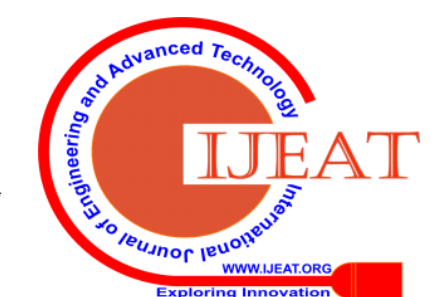

